\title{
Fumigation on bulk cargo ships: a chemical threat to seafarers
}

\section{Rune Djurhuus}

Department of Occupational Medicine, Norwegian Centre for Maritime and Diving Medicine, Haukeland University Hospital, Bergen, Norway

\section{ABSTRACT}

Fumigation is a process that is carried out to prevent deterioration of goods by pests and spread of unwanted organisms for example during long-distance carriage by sea. Several intoxications due to use of pesticides on bulk cargo ships have been indicated, but for some of these incidents the documentation are questionable. The objective of the present study was therefore to examine the extent of the problem by collecting available information of incidents or intoxications due to use of pesticides on bulk cargo ships. Information sources such as PubMed, Google Scholar, Gard (marine insurance company), Marine Accident Investigation Branch, United Kingdom, and Professional Mariner (a magazine) were searched using similar search phrases.

The results indicate that the present practice of fumigation with pesticides of cargo holds on bulk ships represents a serious health risk to both seafarers and port workers. A thorough search for information in both scientific and non-scientific sources revealed a number of intoxications including several fatalities. According to the available documentation, phosphine seems to be used more or less exclusively as fumigant on bulk cargo ships today. Phosphine has a high acute toxicity, and recent findings suggest long-term effects. Several of the reported incidents point to lack of knowledge and neglecting of recommended procedures as key elements in this respect. The problem is likely underestimated due to lack of available documentation of several incidents. Preventive actions should be implemented that focus on documentation of incidents, increase knowledge of pesticide health hazard and implementation of safety procedures that are mandatory to perform when fumigated cargo is to be handled on bulk ships.
\end{abstract}

(Int Marit Health 2021; 72, 3: 206-216)

Key words: intoxication, phosphine, pesticide, seaman, chemical hazard, fumigated cargo

\section{INTRODUCTION}

Fumigation is a process that is carried out to prevent deterioration of goods by pests and spread of unwanted organisms for example during long-distance carriage by sea. Accordingly many freight container units and bulk cargo holds on ships are treated with different chemical pesticides termed fumigants. They are termed so because the pesticides are gaseous (usually applied as a "fume") and easily penetrate the cargo, but they may also escape the cargo holds or containers if these are not properly sealed. Unfortunately, these chemicals are also highly toxic to humans, and therefore represent a potential health risk to the crew on board if fumigated cargo leak gaseous pesticides while at sea. In addition, residual pesticides may still be present on arrival at the destination, representing a potential health hazard to dock workers unloading the cargo, ships' crew, custom officers, and workers at warehouses receiving fumigated freight containers.

Recently, our Department of Occupational Medicine completed a comprehensive report regarding health risks of fumigated freight containers, commissioned by the European Agency for Safety and Health at Work (EU-OSHA) [1]. The report concluded that the fumigation problem seems to be underestimated, probably due to lack of documen-

Rune Djurhuus, PhD, Department of Occupational Medicine, Norwegian Centre for Maritime and Diving Medicine, Haukeland University Hospital, N0-5021 Bergen, Norway, e-mail: RuneDjurhuus@outlook.com

This article is available in open access under Creative Common Attribution-Non-Commercial-No Derivatives 4.0 International (CC BY-NC-ND 4.0) license, allowing to download articles and share them with others as long as they credit the authors and the publisher, but without permission to change them in any way or use them commercially. 
Table 1. Overview of major pesticides used for fumigation of freight containers. All the compounds listed have significant toxic potential, including both acute and long-term effects

\begin{tabular}{|c|c|c|c|c|c|c|}
\hline Pesticide & CAS-no. & Mol. weight & $\begin{array}{l}\text { Physical state } \\
\text { bp }\left[{ }^{\circ} \mathrm{C}\right]^{*}\end{array}$ & $\begin{array}{l}\text { OEL } \\
\text { [ppm]** }\end{array}$ & $\begin{array}{l}\text { IDLH } \\
\text { [ppm]§ }\end{array}$ & $\begin{array}{l}\text { Group } \\
\text { IARC† }\end{array}$ \\
\hline Methyl bromide (MeBr) & $74-83-9$ & 94.94 & g; 3.5 & $5\left(1^{\#}\right)$ & 250 & 3 \\
\hline Phosphine $\left(\mathrm{PH}_{3}\right)$ & $7803-51-2$ & 34 & g; -87.7 & 0.1 & 50 & $\mathrm{nc}$ \\
\hline Formaldehyde & $50-00-0$ & 30.03 & g; -19.5 & 0.3 & 20 & 1 \\
\hline Chloropicrin & $76-06-2$ & 164.38 & liq; 112 & 0.1 & 2 & $\mathrm{nc}$ \\
\hline 1,2-Dichloroethane & $107-06-2$ & 98.96 & liq; 83-84 & 1 & nv & $2 B$ \\
\hline Ethylene oxide & $75-21-8$ & 44.05 & $\mathrm{~g} / \mathrm{liq} ; 10.7$ & 1 & 800 & 1 \\
\hline
\end{tabular}

*Physical state at room temperature; bp - boiling point; $\mathrm{g}$ - gas; liq - liquid

$* \star \mathrm{OEL}$ - Occupational exposure limit (time-weighted average for $8 \mathrm{~h}$ exposure), in Finland [42], Sweden [43], Denmark [44] \#OEL in Germany [45]

§IDLH - Immediate Dangerous to Life or Health, National Institute for Occupational Safety and Health [46], USA; nv - no value

${ }^{\dagger}$ Carcinogenicity classification by International Agency for Research on Cancer [47]. 1: Carcinogenic to humans; 2A: Probably carcinogenic to humans; 2B: Possibly

carcinogenic to humans; 3 : Not classifiable as to its carcinogenicity to humans; 4: Probably not carcinogenic to humans; nc - no classification by IARC

CAS-no - Chemical Abstracts Service Registry Number

tation of incidents. Moreover, lack of appropriate labelling and safe procedures for unloading containers based upon appropriate risk assessments seemed to be major elements of the problem.

The present review is complementary to this report, addressing the potential health hazard of the fumigation process related to sea transport of bulk cargo.

\section{FUMIGATION AND HEALTH HAZARDS ON BULK SHIPS}

Fumigation of cargo transported in bulk on cargo vessels represents a considerable health hazard to the ships' crew, and has led to a number of intoxications including fatalities. In contrast to fumigation of containers where several different pesticides may be used as shown in Table 1 [1], fumigation on bulk cargo ships today seems to be almost exclusively carried out using phosphine $\left(\mathrm{PH}_{3}\right)$ as the fumigant. However, the history of treating ships' cargo with pesticides is approximately 100 years old, starting with hydrogen cyanide ( $\mathrm{HCN})$ as the fumigant [2]. At this time, performing the fumigation without sufficient skills and competence resulted in a number of intoxications and several deaths [3]. Later, methyl bromide ( $\mathrm{MeBr}$ ) was used as the preferred pesticide for several stored food commodities in warehouses, grain silos, flourmills, ships' holds, etc. [4]. According to Brodniewicz [5], the compound was frequently used for fumigation of agricultural food products in many ports of the Far East.

\section{DOCUMENTATION OF INCIDENTS ON BULK CARGO SHIPS}

Documentation of intoxications is an important issue since without adequate documentation it is difficult to convince both authorities and industry (logistic companies, ship-owners, etc.) of the real hazard and that mitigating actions are required. Our previous investigation [1] had also indicated that intoxications on bulk ships involved more severe effects and with some more documentation than incidents with freight containers. Nevertheless, the impression was that the documentation was insufficient and the problem probably underestimated.

The objective of the present study was therefore to reveal the extent of the problem by collecting available information of intoxications due to use of pesticides on bulk cargo ships. Both scientific and non-scientific sources were used.

\section{METHODS}

\section{PUBMED SEARCH}

A literature search was conducted using PubMed in October 2020 with subsequent weekly updating. The search was limited to the title/abstract field since search in all fields returned a large number of non-relevant hits that contained the search words in e.g. the reference list or in affiliations of authors.

The following search string in the title/abstract field was used without any time limits: (fumigant OR fumigants OR fumigation OR fumigated OR fumigating OR pesticide OR pesticides OR toxic OR intoxication OR intoxications OR intoxicated OR intoxicating OR poison OR poisoned OR poisoning OR poisonous OR "methyl bromide" OR phosphine OR formaldehyde OR chloropicrin OR 1,2-dichloroethane OR "ethylene oxide") AND (ship OR ships OR freighter OR seafarer OR seafarers OR seaman OR seamen OR maritime).

The search returned 411 references, and the oldest one was from 1893. The papers were examined by title and abstract. Only articles that concerned fumigation by pesticides on bulk cargo ships and related intoxications on humans were included, excluding papers concerning fumigation of freight containers only. 
Five possibly relevant papers based upon title were without abstract and inaccessible due to language (two Italian, two Russian and one of undetermined language according to PubMed), but since they were from 1968 or older they probably would have minor impact on the perception of today's situation. That left 9 relevant papers of the 411 hits. Weekly updating of the search has so far not retrieved any additional relevant records.

Updated information regarding phosphine toxicity in general was collected in March 2020, using the following search string in the title/abstract field without time limits: phosphine AND (toxic OR toxicity OR toxicology OR poison OR poisoning OR poisoned OR poisonous OR intoxication OR intoxicated).

The search returned 364 references, 88 of these were from the period 2017-2020. Twenty of 364 were review articles. Only recent reviews and articles containing general toxicological information on phosphine were considered relevant in this respect.

\section{GOOGLE SCHOLAR SEARCH}

In contrast to PubMed, Google Scholar has several limitations with respect to literature search. It contains only two options with respect to search field, and that is either in Title only or in the full text document. Search in title only may be too narrow, but search in the full text document will include hits from reference list even if the document itself does not contain any of the words in the search string. Moreover, there is a limit of 256 characters in the search field, truncation does not function, no more than 1000 results can be displayed, the sequence of search phrases influences the result, and the results are not completely reproducible. For a comprehensive evaluation of Google Scholar as a search engine for literature, see [6].

Due to these limitations the Google Scholar search was conducted (February 2021) using the following search phrase in full text documents in English or German language and initially without any time limit: (fumigation OR fumigated) (intoxication OR intoxicated OR poison OR poisoning OR poisonous) (ship OR freighter OR seafarer OR seaman OR maritime).

The initial search returned 5420 hits. Since the most acknowledged documents assumingly had been collected from the PubMed search, and additional documents older than 10 years now would have more historic impact than reflecting today's situation, the search was then limited from 2010 to present. That returned 1634 hits, but due to the limit described above the records were screened for one year at a time.

Only two of the documents contained information that was not identified by the PubMed search and thus relevant for the fumigation on bulk cargo ships. One of the documents referred to an incident on a bulk vessel, and a comprehensive report of that incident was subsequently retrieved [7].

An example of seemingly relevant, but still not useful information was the Annual Report of the American Association of Poison Control Centres' National Poison Data System [8]. It contained a table describing all exposures by nonpharmaceuticals that included incidents with fumigants like phosphine and methyl bromide, but without any information of the circumstances of the incidents, i.e. if it happened during fumigation of a house, a garden, warehouse, container or a bulk ship. The information is therefore of little value in the present context. A personal communication with the Norwegian Poison Information Centre revealed that they would not release information regarding intoxications due to fumigation except gross numbers of persons intoxicated by a given chemical in a defined period of time, no information of the circumstances, age, gender, etc., primarily due to protection of personal privacy. It is likely that similar restrictions apply to other national poison centres. The exception is if the poison centres themselves publish papers that describe a number of incidents related to an actual problem. A recent example of the latter is the paper from the Belgian Poison Centre that described 18 incidents reported to the Centre. Most of the incidents were related to work with fumigated containers, only a few were related to fumigated bulk cargo ships, and the information presented for each case was limited [9].

\section{OTHER INFORMATION SOURCES}

Gard - marine insurance company. Search using the same search words as for the PubMed search returned only one relevant hit: "Fumigation of cargo on board ships: the invisible killer", an article in the company's own newsletter, Gard News, containing several examples of intoxications by fumigants on bulk ships.

Marine Accident Investigation Branch (MAIB). A unit within the United Kingdom (UK) Department of Transport that investigates marine accidents involving UK-vessels. MAIB issues reports and safety flyers based on the incidents. The documents found on MAIB consist of "Current investigations" and "MAIB reports". The former contained only 31 publications and was easily screened. MAIB reports contained 971 reports, and excluding the reports comprising fishing vessels and recreational crafts left 648 reports. Using similar words as in the PubMed search returned two relevant hits that described incidents on two different vessels.

Professional Mariner. A magazine owned by Navigator Publishing LLC focusing on training and licensing, maritime casualties, technology, engineering and regulatory issues 


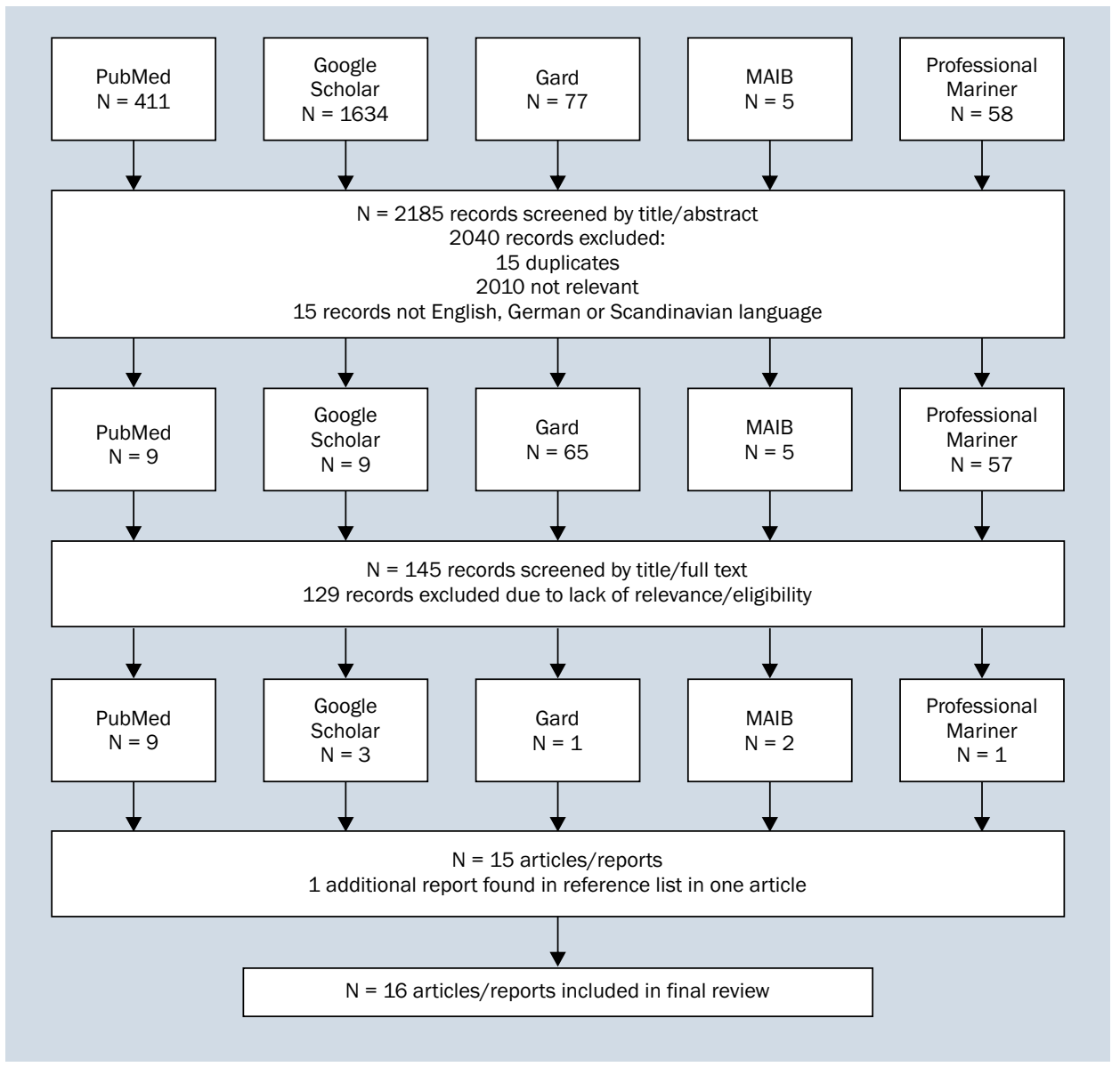

Figure 1. Flow chart of the literature review. Records were initially identified through search in relevant databases and information sources using similar search phrases without time limits. The Google Scholar search excluded records that were not in English or German language and was limited to the period after 2009 (for details see Methods). The Marine Accident Investigation Branch (MAIB) search included all current investigations and all published investigation reports and safety bulletins excluding those on fishing vessels and recreational crafts

related to commercial maritime vessels of all types in the United States (US) and Canada since 1993. Using the similar search words as for the PubMed search returned two relevant hits, both describing the same incident on a bulk ship in 2010.

All relevant papers, reports or documents were used for summarising and listing of reported intoxications due to fumigation on bulk cargo ships. A flow chart summarising the literature review is shown in Figure 1.

\section{RESULTS AND DISCUSSION}

The results from the literature review identified only $\mathrm{MeBr}$ and $\mathrm{PH}_{3}$ as the cause of documented intoxications on bulk cargo ships. Moreover, for the last 40-50 years $\mathrm{PH}_{3}$ seems to be the prevailing compound in use, at least based upon the documented incidents. Accordingly, the present review will reflect these results and focus on those two with a brief description of $\mathrm{MeBr}$ and a more comprehensive presentation of $\mathrm{PH}_{3}$ toxicology.

\section{METHYL BROMIDE AND PHASING OUT AS AN OZONE-DEPLETING AGENT}

Workers may be exposed to $\mathrm{MeBr}$ by inhalation or by the dermal route. It affects primarily the respiratory system and central nervous system (CNS), but also gastrointestinal symptoms have been reported. $\mathrm{MeBr}$ has not been shown to be carcinogenic to humans [10], but other long-term effects seem to be frequent. $\mathrm{MeBr}$ may cause chronic effects like speech impairment, lack of coordination, visual impairment and loss of memory. More details on $\mathrm{MeBr}$ toxicology are available elsewhere (Alexeeff and Kilgore, 1983; de Souza et al., 2013; Bulathsinghala and Shaw, 2014).

In 1987, United Nations arranged the meeting that resulted in the Montreal Protocol on substances that deplete the ozone layer [11]. At the beginning, the protocol comprised rather few substances to be controlled. Methyl bromide was added to the list in 1992, and later amendments increased the number of controlled substances substantially. The resolution on $\mathrm{MeBr}$ in 1992 stated that 
one should make every effort to reduce emissions of and to recover, recycle and reclaim $\mathrm{MeBr}$, without specifying explicit numbers. However, an exemption was agreed to regarding its use for quarantine and preshipment applications (QPS). At the time of the original banning of $\mathrm{MeBr}$, the use for QPS-purposes was small compared to other uses, while today other uses of $\mathrm{MeBr}$ have declined dramatically. In 2017, the consumption of MeBr for QPS-use was reported to 9960 tons, which comprised $97.5 \%$ of the total global use of $\mathrm{MeBr}$, implying that non-QPS use in 2017 was not more than approximately 245 tons. The reported figures also show that the use of MeBr for QPS use has been rather stable for many years [12].

The exemption of $\mathrm{MeBr}$ for QPS-use in the Montreal Protocol urges all parties to seek for alternatives, but so far, this seems to have had little effect on the QPS-use. However, with respect to pest control on bulk cargo carried by sea, it seems that $\mathrm{MeBr}$ is of little use, at least in European waters. Few, if any, documented intoxications by $\mathrm{MeBr}$ the last 30-40 years have been found in public available sources, but this may be different in other parts of the world, since Asian countries accounted for approximately $55 \%$ of the global QPS consumption in 2017 [12]. It may also be a consequence of lack of reporting such incidents.

For those incidents/intoxications that have been reported the last 40 years, it seems that pest control on bulk cargo ships today is almost exclusively by use of $\mathrm{PH}_{3}$ as fumigant. There are several reasons for this; not at least the availability of the substance and the ease of application as outlined below.

\section{PHOSPHINE}

Phosphine holds a unique position among the fumigant pesticides since it is the only one that is usually not applied in gaseous form (fume), but is administered in the form of a metal phosphide like aluminium phosphide (AIP), magnesium phosphide $\left(\mathrm{Mg}_{3} \mathrm{P}_{2}\right)$ or zinc phosphide $\left(\mathrm{Zn}_{3} \mathrm{P}_{2}\right)$. These phosphides are solid materials that react with water vapour (moisture) in the air (equations I-II) and liberate phosphine gas, $\mathrm{PH}_{3}$, which is the active pesticide. Moreover, the fumigation is often carried out as an in-transit process, i.e. during the voyage at sea and may consequently represent a potential health hazard to the entire crew.

$$
\begin{aligned}
& \text { I. } \mathrm{AIP}_{(\mathrm{s})}+3 \mathrm{H}_{2} \mathrm{O} \rightarrow \mathrm{Al}(\mathrm{OH})_{3}+\mathrm{PH}_{3}(\mathrm{~g}) \\
& \text { II. } \mathrm{Mg}_{3} \mathrm{P}_{2(\mathrm{~s})}+6 \mathrm{H}_{2} \mathrm{O} \rightarrow 3 \mathrm{Mg}(\mathrm{OH})_{2}+2 \mathrm{PH}_{3}(\mathrm{~g}) \\
& \mathrm{Zn}_{3} \mathrm{P}_{2} \text { reacts similar as } \mathrm{Mg}_{3} \mathrm{P}_{2}
\end{aligned}
$$

In pure form, phosphine is a colourless and odourless gas. However, impurities from the production process often add a characteristic odour of garlic or decaying fish [13]. $\mathrm{PH}_{3}$ is highly toxic, and animal experiments indicate a steep dose-response curve. Mice inhaling $\mathrm{PH}_{3}$ for 1 hour showed no mortality up to $59.2 \mathrm{ppm}$ (the highest concentration tested), while 4 hours exposure showed no mortality at 26.5 ppm and 100\% mortality at 33.4 ppm, suggesting a $\mathrm{LC}_{50}$ between these two values [14]. Rats exposed to $5 \mathrm{ppm} \mathrm{PH}_{3}$ for 6 hours a day for 13 days showed no significant adverse effects, while $7 \mathrm{ppm}$ was fatal to pregnant rats after 3-10 days of exposure [15]. Similar results were found in a study on mice and rats: No mortality was found after exposure to $5 \mathrm{ppm} \mathrm{PH}_{3}$ for 6 hours a day for 2 weeks, while inhalation of 10 ppm for 4 days was lethal [16]. These studies indicated a threshold for toxic effects around 5-7 ppm and a median lethal dose of approximately $\mathrm{C} \times \mathrm{T}=180$ ppm-hours. Furthermore, the studies indicated that the primary hazard of phosphine exposure was lethality $[15,16]$. A follow-up study with rats inhaling 0.3-3 ppm $\mathrm{PH}_{3}$ for 6 hours/day, 5 days a week for 2 years showed no carcinogenic or other clinical effects, supporting a threshold effect for $\mathrm{PH}_{3}$-toxicity [17]. A recent study confirmed the steep dose-response curve when rats were exposed to 500-1000 ppm $\mathrm{PH}_{3}$ for 20-40 min. No adverse effects were observed after exposure to $10,000 \mathrm{ppm}-\mathrm{min}$, while exposure to $33,000 \mathrm{ppm}$ min resulted in $100 \%$ lethality [18].

Incidents involving humans often lack precise exposure data (e.g. time and concentration) and are difficult to use in estimation of human health risks associated with $\mathrm{PH}_{3}$-exposure. Accordingly, governmental recommendations like the US Acute Exposure Guideline Levels for Selected Airborne Chemicals (AEGLs) mainly rely on animal data [19]. Species variations seem to be minimal, since dose-response data on lethality obtained from rats, rabbits, guinea pigs and cats followed the same curve when exposure concentration was plotted against exposure time. They also indicated a threshold value of 3-5 ppm, below which no adverse effects seemed to occur [13].

Typical symptoms of $\mathrm{PH}_{3}$-intoxication in humans are respiratory effects with pulmonary oedema, cardiac failure and hepatic failure $[20,21]$. Most incidents with fatalities describe pulmonary and circulatory failure and ultimately cardiac arrest. Cardiotoxicity was described in a case report of three stowaways in a railcar loaded with rice and fumigated with phosphine. One was found dead; the two others were brought to intensive care unit at the hospital. One died 12 hours later, and premortem echocardiogram revealed an ejection fraction of only $10 \%$. The third subject showed an ejection fraction of $15 \%$, with improvements to $40 \% 3$ days later. He recovered and was discharged from hospital on day 8 after the incident [22].

The precise mechanism of phosphine toxicity is still not elucidated. Early studies using both animal and human data indicated that inhibition of mitochondrial respiration was a common critical effect. Moreover, several in vitro studies 
indicated that complex IV of the electron transport chain (ETC) was the molecular target, i.e. cytochrome $c$ oxidase [23]. Neurological effects have also been reported, suggesting that $\mathrm{PH}_{3}$ increases neurotransmission by inhibiting acetylcholine esterase (AChE) [24]. A study on fumigators in USA using $\mathrm{PH}_{3}$ indicated that they had a decrease in plasma choline esterase (ChE) of at least 20\% [25]. However, a similar study from Australia on 31 fumigators using $\mathrm{PH}_{3}$ and with an average personal exposure at $1 \mathrm{ppm}$ for 2 hours (determined for 3 of them) found no effect on ChE, and no other toxic effects [26].

Many of the studies on acute effects of phosphine in humans are limited to accidental or intentional ingestion (suicide) of high doses of metal phosphides like aluminium phosphide (AIP). Although a widespread assumption is that the toxicity of the metal phosphides proceeds via the internal liberation of phosphine gas in the body, the toxicological mechanism may not be the same for ingestion of a metal phosphide as for the absorption of gaseous $\mathrm{PH}_{3}$ through the lungs. In particular, there have been suggestions that the metal itself may have a considerable effect on ChE and may be one explanation for the difference that has been observed on ChE after in vitro exposure to $\mathrm{PH}_{3}$ gas compared to effects in vivo after ingestion of AIP. In addition, some data indicate that $\mathrm{PH}_{3}$ only partly inhibits cytochrome $c$ oxidase in vivo [24].

Several animal studies have indicated that the major hazard from $\mathrm{PH}_{3}$ exposure is lethality, with no long-term effects $[16,17,27]$. The view of mainly acute effects was supported by case reports describing recovery of subjects from acute intoxications without observable long-term effects. The fact that breakdown products of $\mathrm{PH}_{3}$ are stable phosphorous oxides that enter normal cellular metabolism as phosphate [20], and that inhibition of energy metabolism may be reversible, also point to acute toxicity as the major effect of $\mathrm{PH}_{3}$-poisoning [23]. A few epidemiological studies of workers exposed to $\mathrm{PH}_{3}$ gas had also indicated lack of adverse health effects at concentrations up to $7 \mathrm{ppm}$ (reviewed by [23]), an observation in line with the threshold observed in animal studies [15, 16, 18].

In 1978, an intoxication by phosphine occurred on a bulk cargo ship that affected 29 crewmembers in addition to the captain's wife and 2 children. Sadly, one of the children died, but the others recovered completely. All clinical symptoms and laboratory findings were normalised a week after the incident, although the authors noted, "little is known, however, about possible long-term effects of sustained low-dose phosphine exposure" [28]. A more recent case report further adds to the view of only acute effects of phosphine: 6 family members ( 2 adults and 4 children) in a home where AIP was used to kill voles in their yard were exposed to the $\mathrm{PH}_{3}$ gas; 2 of the children died, but the other 4 recovered without any long-term symptoms reported [29].
Few studies regarding long-term effects are available. As cited above, one of the few long-term animal studies that have been conducted showed no effects after inhalation of 0.3-3.0 ppm $\mathrm{PH}_{3}$ for 2 years [17]. However, some human data describe both persistent neurological and respiratory effects. Two cases of phosphine-exposure for 30-60 min indicated long-term effects in addition to acute intoxications. One of them showed signs of obstructive airway disease 3 months later, while the other was diagnosed with peripheral neuropathy 8 months after the incident [30].

A recent study on rats exposed to 500-1000 ppm $\mathrm{PH}_{3}$ (g) for 10-40 min demonstrated increased respiration and pulmonary damage, mitochondrial compromise and myofibril degeneration of left ventricular tissue. Notably, the results showed cardiac-specific alterations in gene expression indicating inflammation and metabolic aberrations in the heart that might result in long-term effects [18]. Adding to this, a recent paper reported that 13 of 15 crewmembers surviving an accidental exposure to $\mathrm{PH}_{3}$ on a bulk cargo ship had clinical symptoms 3 months after the incident [31]. In particular, one crewmember showed subclinical left ventricular dysfunction 4 months after the same incident [32].

These reports suggest that $\mathrm{PH}_{3}$-exposure may have persistent adverse effects on both the respiratory, cardiac and central nervous systems.

\section{INTOXICATIONS BY PESTICIDES ON BULK CARGO SHIPS}

As indicated above, treating of ships' cargo with pesticides started almost 100 years ago. The first intoxication due to fumigation on a bulk cargo ship that is well described in a scientific paper occurred at the port of Haiphong in Vietnam in 1958. A Polish bulk ship was loaded with rice and had the cargo fumigated with MeBr. The crew stayed on board throughout the fumigation process, and shortly before leaving the port 10 crewmembers got ill, one of them died soon after. Medical examinations confirmed that the cause was poisoning by $\mathrm{MeBr}$. The incident was not made public until 1967 when Brodniewicz [5], a former head of the Department of Disinfection at the State Institute of Hygiene in Warsaw, Poland, published a paper that in detail described the incident. However, since then no reports neither in the scientific literature nor in the grey literature has been found describing incidents on bulk cargo ships involving $\mathrm{MeBr}$. In this respect, it seems that $\mathrm{PH}_{3}$ has replaced $\mathrm{MeBr}$ as fumigant, and today $\mathrm{PH}_{3}$ seems to be almost exclusively used for pest control on bulk cargo ships as indicated above.

One of the first intoxications by $\mathrm{PH}_{3}$ on a bulk ship was reported in 1962, but this was not due to fumigation. It was a ship loading barrels with ferrosilicon in Bremen, Germany. One of the barrels was damaged during the loading such that the content leaked out on the floor of the cargo hold. 
Due to rainfall during the operation, the floor was wet, and since the ferrosilicon had a minor content of metal phosphide (e.g. $\mathrm{Ca}_{3} \mathrm{P}_{2}$ ), it released $\mathrm{PH}_{3}$ gas after contact with the water. None of the crewmembers was informed of the possible hazard from the cargo, and unfortunately, some of the crew's cabins were located right on top of the hold, and $\mathrm{PH}_{3}$-gas leaked into the cabins. Three seafarers were intoxicated, two of them with fatal outcome [33].

Since then a number of incidents arising from fumigation with phosphine have been reported, including several fatalities. One of the first detailed descriptions occurred on a bulk cargo ship in 1978 and affected 29 crewmembers in addition to the captain's wife and two children including one fatality. The cargo had been fumigated using AIP-tablets that were spread on top of the grain load just before leaving the port [28]. This is the typical procedure for use of this fumigant and it illustrates one of the main reasons for using $\mathrm{PH}_{3}$ as pesticide: its ease of application. Usually a metal phosphide (AIP, $\mathrm{Mg}_{2} \mathrm{P}_{3}, \mathrm{Zn}_{2} \mathrm{P}_{3}$ ) in the form of tablets, pellets, granulates or powder is packed in small sachets or textile hoses/socks. These are just buried in the cargo (e.g. in grain) or left on the top of the cargo (or in some cases without any packaging) as shown on Figure 2. The reaction with moisture in the air starts almost immediately releasing $\mathrm{PH}_{3}$, and then the holds are sealed. Since $\mathrm{PH}_{3}$ is slightly heavier than air, it sinks to the bottom of the hold penetrating the grain and kills the pests throughout the cargo. The fumigators carrying out this process usually wear proper protection equipment like gas masks or self-contained breathing apparatus (SCBA). The fumigation process is usually carried out in port, but after the fumigators have left the ship, the ship often sails. If the moisture content in the cargo holds' air is sufficient, the reaction will be completed during the sea voyage, and the holds may be ventilated to let out the remaining gas while still at sea. In some cases, however, the moisture content is limited, and the reaction will cease before completion, leaving solid residues of metal phosphide. When the holds are opened at the destination, fresh air with moisture will enter the holds and the reaction will restart releasing $\mathrm{PH}_{3}$ gas. An example of this was seen when the bulk ship Arklow Meadow arrived in the port of Warrenpoint in Northern Ireland in December 2012. Both crewmembers and port workers were affected, but due to rapid evacuation of both the ship and unloading area, serious health effects were avoided [34].

Performing the fumigation process while the ship is at sea (in-transit fumigation) represents a serious health hazard to the entire crew. As indicated above, several of the ships involved are not technically suited for this process. Tiny holes in the fumigated holds may lead to escape of $\mathrm{PH}_{3}$-gas into other parts of the ship, e.g. living quarters. Indeed, there are several examples of that, for example the incident on MV Monika in 2007 where a young seafarer died due to $\mathrm{PH}_{3}$-poi-

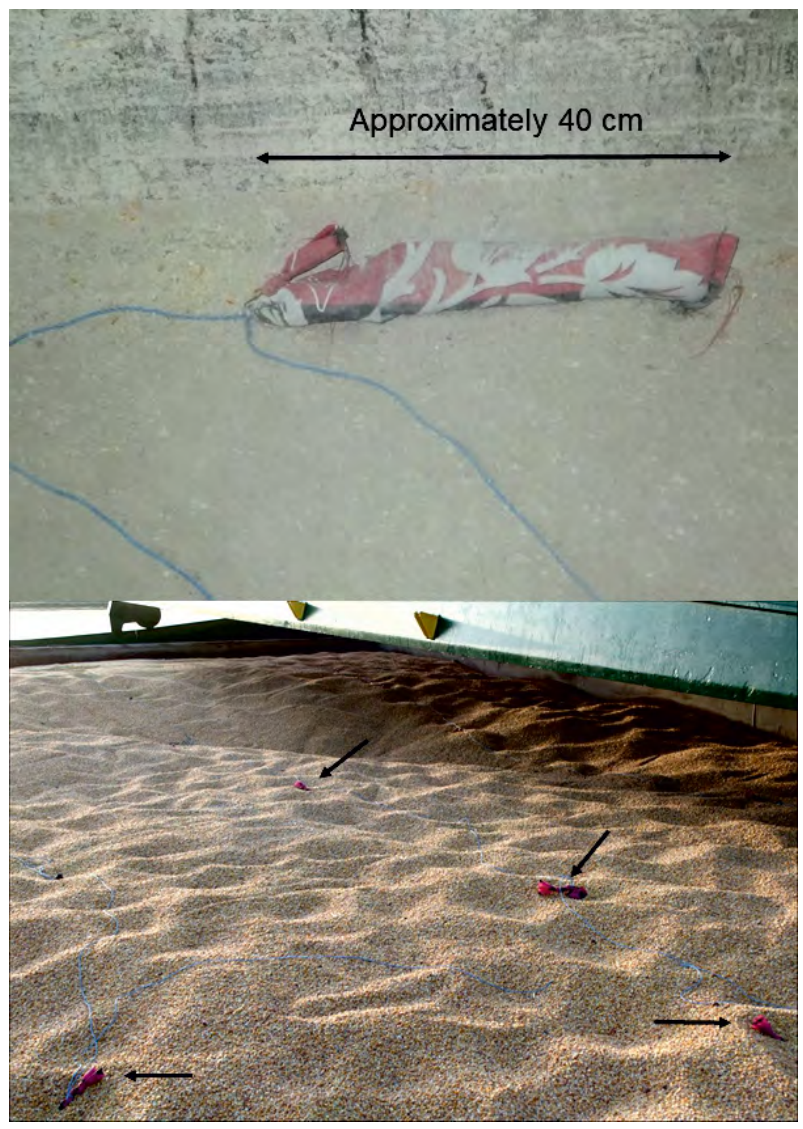

Figure 2. Example of fumigation by aluminium phosphide on board a bulk ship. Top panel: A typical fabric retainer or "sock" containing solid aluminium phosphide (AIP). Bottom panel: Distribution of aluminium phosphide in "socks" (indicated by black arrows) on top of a grain cargo on a bulk ship. The photographs are from the bulk ship Arklow Meadow at port of Warrenpoint, Northern Ireland, December 2012 and are reproduced with permission from Marine Accident Investigation Branch (MAIB), Southampton, United Kingdom

soning. His cabin was located straight above the cargo hold, and inspection after the incident revealed pinholes into the cabin from the cargo hold [35]. Similar conditions led to the death of a seafarer on board a bulk cargo ship in 2008 , while four others recovered from adverse symptoms [36].

A rather comprehensive review of several intoxications was found as a non-scientific article from the insurance company Gard [37]. The article described seven different incidents in the period from 1997-2010, occurring in European, American and African waters. All incidents were due to fumigation with $\mathrm{PH}_{3}$, and in most cases by using solid AIP tablets, usually placed on top of the cargo. A typical scenario was that fumigators entered the ship in port, distributed AIP tablets on top of the cargo or partially buried in the cargo, closed and sealed the hatches of the holds and left the ship. Shortly after the ship sailed, and after a few days at sea some crewmembers started to show signs of poisoning. 
Table 2. Reported pesticide intoxications on bulk ships

\begin{tabular}{|c|c|c|c|c|c|}
\hline \multirow[t]{2}{*}{ Vessel, location, cargo } & \multirow[t]{2}{*}{ Year } & \multirow[t]{2}{*}{ Pesticide } & \multicolumn{2}{|c|}{ No. affected } & \multirow[t]{2}{*}{ Reference } \\
\hline & & & All & Deaths & \\
\hline MS Marian Buczek, Haiphong, Vietnam, rice & 1958 & $\mathrm{MeBr}$ & 10 & 1 & {$[5]$} \\
\hline MV Thermopylai, Canada-USA, grain & 1978 & $\mathrm{PH}_{3}$ & 31 & 1 & [28] \\
\hline Danish vessels & $1988-1996$ & $\begin{array}{l}\mathrm{un}^{*} \\
\mathrm{PH}_{3}\end{array}$ & $\begin{array}{l}4 \\
2\end{array}$ & $\begin{array}{l}3 * * \\
1 * *\end{array}$ & {$[48]$} \\
\hline Geared bulker, Brazil, soy bean meal & 1997 & $\mathrm{PH}_{3}$ & 5 & 0 & {$[37]$} \\
\hline Bulk carrier, West Coast, USA, soy bean meal & 2000 & $\mathrm{PH}_{3}$ & 12 & 0 & {$[37]$} \\
\hline Bulk cargo vessel, Panama, timber & 2006 & $\mathrm{PH}_{3}$ & $2 \#$ & 0 & {$[37]$} \\
\hline MV Monika, North Sea, wheat & 2007 & $\mathrm{PH}_{3}$ & 1 & 1 & [35] \\
\hline Bulk cargo vessel, Bretagne, France, peas & 2008 & $\mathrm{PH}_{3}$ & 5 & 1 & {$[36]$} \\
\hline Cargo vessel, Lagos, Nigeria, cocoa beans & 2009 & $\mathrm{PH}_{3}$ & $6 * \star$ & $1 * *$ & {$[37]$} \\
\hline General cargo ship, Antwerp, Belgium, wheat & 2010 & $\mathrm{PH}_{3}$ & 2 & 1 & [37] \\
\hline MV Herman Schoening, Lake Erie, Canada/USA, grain & 2010 & $\mathrm{PH}_{3}$ & 16 & 0 & [37], [49] \\
\hline MV Arklow Meadow, Warrenpoint, Northern Ireland, maize & 2012 & $\mathrm{PH}_{3}$ & $13 \S$ & 0 & {$[34]$} \\
\hline MV Nefryt, Gulf of Guinea, Ivory Coast, shea nuts & 2015 & $\mathrm{PH}_{3}$ & 17 & 2 & [7] \\
\hline Six bulk cargo vessels, Ukraine & $2006-2016$ & $\mathrm{PH}_{3}$ & 66 & 9 & [39] \\
\hline Bulk cargo ship, Antwerp, Belgium & 2014 & $\mathrm{PH}_{3}$ & $1 \dagger$ & 0 & [9] \\
\hline MV Nazmehr, Caspian Sea, grain & 2018 & $\mathrm{PH}_{3}$ & 15 & 3 & {$[38]$} \\
\hline
\end{tabular}

*Unidentified pesticide; **Stowaways; \#Fumigators; §8 crew, 1 stevedore and 4 port workers; †Port worker; $\mathrm{PH}_{3}-$ phosphine; $\mathrm{MeBr}-$ methyl bromide

For some of the incidents the $\mathrm{PH}_{3}$-gas escaped through tiny holes or leakages from the cargo holds and into the accommodation area, while in some cases the gas was distributed by a defect ventilation system. In total for all the 7 incidents, 43 individuals were affected including 3 fatalities. The report points to several factors that contributed to the intoxications including lack of following International Maritime Organization (IMO)-recommendations when performing the fumigation, lack of knowledge of crewmembers regarding the hazard of the fumigant, no use of monitoring equipment and lack of knowledge of poisoning symptoms. Furthermore, some vessels seemed unsuitable for cargo fumigation due to lack of properly sealed boundaries between cargo holds and crew quarters.

Another severe incident occurred in September 2015 at the port of Abidjan, Ivory Coast. In contrast to many other incidents this one has been thoroughly described by the State Marine Accident Investigation Commission of Poland [7]. A Polish ship had been loading shea nuts, and just before leaving port 2 persons came on board to fumigate the cargo. They distributed AIP tablets on top of the cargo, and then the hatches of the holds were closed. During the distribution of the AIP tablet a sharp, unidentified odour was noted, but the chief officer did not receive any information or warning leaflets about the possible effects of the fumigant. The chief officer then advised the crew not to inhale any smelling gas when they closed the hatches. Approximately 1 day later the crew started to complain of stomach pains and vomiting, and the conditions soon became worse. In the end, all 17 crewmembers were intoxicated, and eventually two of them died. Moreover, long-term effects were indicated as 13 of the 15 surviving crewmembers still showed clinical symptoms 3 months later, and one showed cardiovascular effects even 4 months after the incident as indicated above [31, 32].

The most recent documented incident occurred on an Iranian bulk ship transporting grain on the Caspian Sea in October 2018. Fumigation was performed using AIP tablets just before the vessel left port in Kazakhstan, and while the ship was at sea 15 crew members were severely intoxicated by phosphine, three of them with fatal outcome. According to the author, failure of safety requirements, decrepitude of the vessel and leakage from the cargo holds were the main reasons for the accident [38].

As reported from the incident with Arklow Meadow above, dockworkers may also be at risk during unloading of the cargo. A recent paper reported intoxication of a dockworker at the port of Antwerp, Belgium, during unloading of a cargo ship that had been fumigated with $\mathrm{PH}_{3}$ [9]. Still, the majority of the reported intoxications involve seafarers only. An overview of the incidents found from the information search is presented in Table 2. Of the at least 21 incidents shown in the Table 2, only two of these clearly indicate intoxication of port workers. 
It should be emphasised that a number of the incidents presented in Table 2 are not reported in the scientific literature, are of variable quality with respect to details of the incidents, long-term follow-up of the victims, etc., and are not easily available. This leads to the speculation that a number of additional incidents are not properly reported and documented. Appropriate documentation is a prerequisite for a realistic perception of the hazard. Nevertheless, the incidents listed in Table 2 and the available information on $\mathrm{PH}_{3}$-toxicity in general underpin the need for serious efforts to address the problem and increase the safety of both the seafarers and port workers.

Details from the reported intoxications strongly indicate that there is a lack of knowledge of the hazard of the fumigation, both by the fumigators and not at least by the crewmembers on board the fumigated ships. This is emphasised in a recent report that also points to misinterpretation of symptoms as food intoxications due to lack of qualified medical knowledge. For several incidents the result was inadequate medical care with severe outcomes including fatalities [39]. In addition, the report notes that in most cases the ships were old and not technically prepared for the transport of fumigated cargoes and often lacked methods and equipment for monitoring possible leaks of poisonous gas from the holds.

Compared to the health hazards of fumigated freight containers as documented in our recent EU-OSHA-report [1], the problem with fumigated cargo on bulk ships seems to include more severe intoxications, a considerable number of fatalities and more documentation of the incidents. Nevertheless, the documentation of intoxications due to fumigation on bulk cargo ships is still limited, and the extent of the problem is probably underestimated. Improved documentation and publication of incidents is required to get sufficient attention to the problem.

\section{REGULATIONS IMO}

The IMO has issued detailed recommendations with respect to fumigation, including in-transit fumigation that often is carried out using phosphine [40]. Compliance with these recommendations would reduce the health hazard considerably. The impression from the cases reported above, however, is that in many cases these instructions are at least partly neglected. An illustrating example is the case of fumigation on board MV Nefryt that led to the loss of two lives. The following investigation revealed that human factors were the main reason for the intoxication, and lack of compliance with requirements in ship-owner's by-laws and international requirements on ship cargo fumigation were major factors in this respect [7]. Similar marine casualties also seem to be caused by human factors including lack of knowledge and ignoring established procedures and recommendations [39, 41].
Technical conditions of the vessels seem also to play an important part, for example with leakages from the ships' holds to the accommodation area [35, 37-39]. In addition, misinterpretations of symptoms as seasickness or food intoxications have also been involved in cases with fatal outcome [35, 39].

\section{CONCLUSIONS}

The present practice of fumigation with pesticides of cargo holds on bulk ships represents a serious health hazard to seafarers and port workers. Search for information in both scientific and non-scientific sources revealed a number of intoxications including several fatalities. Several of the incident reports point to lack of knowledge and neglecting of recommended procedures as key elements in this respect. The problem is likely underestimated due to lack of available documentation. Preventive actions should include documentation of incidents, increased knowledge of pesticide health hazard and implementation of safety procedures that are mandatory to perform when fumigated cargo is transported on bulk ships.

\section{RECOMMENDATIONS}

Preventive actions are required to reduce the health risk to the seafarers. Knowledge is a key point in this respect. All crewmembers must acknowledge the hazard from the fumigant and be thoroughly drilled of what precautions to implement. There should be written instructions in a language that all crewmembers can read on how to act when on board a fumigated ship.

Preferentially, the fumigation should be carried out in port by professional fumigators while the ship's crew is evacuated, and the ship should not sail until the fumigation process have been completed, the holds have been ventilated and residual fumigant concentration has been documented to be below recognised safe levels using adequate measuring equipment.

Measuring equipment for $\mathrm{PH}_{3}$ (or other actual fumigant) should be available throughout the sea voyage, and a number of crewmembers should be trained in using it. $\mathrm{PH}_{3}$-concentration in the ambient air of living quarters, mess room, etc. should be monitored routinely throughout the sea voyage. Personal protective equipment including gas masks and/or SCBA should be available and the crew should be trained in using them.

As indicated above, documentation of incidents is extremely important, as future mitigating actions will rely on a realistic perception of the problem. Accordingly, there should be a system for reporting incidents and make it public available to both seafarers and professionals engaged in occupational safety, preferably in scientific, referee-based journals. 


\section{ACKNOWLEDGEMENTS}

The author wishes to thank the Marine Accident Investigation Branch (MAIB), Southampton, United Kingdom, for kindly providing photographs illustrating fumigant administration on bulk cargo ships.

\section{Conflict of interest: None declared}

\section{REFERENCES}

1. Bråtveit M, Djurhuus R, Kirkeleit J, et al. Human health risks and prevention practises during handling of fumigated containers in ports. European Agency for Safety and Health at Work (EU-OSHA). 2018. https://osha.europa.eu/en/publications/handling-fumigated-containers-ports-health-risks-and-prevention-practices/view.

2. Liston WG, Gore SN. The fumigation of ships with Liston's cyanide fumigator. J Hyg (Lond). 1923; 21(3): 199-219, doi: 10.1017/ s0022172400031430, indexed in Pubmed: 20474773.

3. Bilderbeck CL. A practical note on the cyanide fumigation of ships. Ind Med Gaz. 1932; 67(4): 200-207, indexed in Pubmed: 29010893.

4. Alexeeff GV, Kilgore WW. Methyl bromide. Residue Rev. 1983; 88: 101-153, doi: 10.1007/978-1-4612-5569-7_3, indexed in Pubmed: 6348905.

5. Brodniewicz A. Poisoning of seamen with methyl bromide due to fumigation of a Polish cargo ship in Haiphong (Vietnam). Arh Hig Rada Toksikol. 1967; 18(1): 19-24, indexed in Pubmed: 6043110.

6. Boeker M, Vach W, Motschall E. Google Scholar as replacement for systematic literature searches: good relative recall and precision are not enough. BMC Med Res Methodol. 2013; 13: 131, doi: 10.1186/1471-2288-13-131, indexed in Pubmed: 24160679.

7. SMAIC. Very serious marine casuality - MV Nefryt. State Marine Accident Investigation Commission, Warsaw, Poland. 2016. https:// pkbwm.gov.pl/wp-content/uploads/images/uchwaly_raporty/ raporty/Final_report_Nefryt_WIM_47_15.pdf.

8. Gummin DD, Mowry JB, Spyker DA, et al. 2018 Annual Report of the American Association of Poison Control Centers' National Poison Data System (NPDS): 36th Annual Report. Clin Toxicol (Phila). 2019; 57(12): 1220-1413, doi: 10.1080/15563650.2019.1677022, indexed in Pubmed: 31752545.

9. Van de Sijpe P, Lucas D, Canals ML, et al. Acute occupational phosphine intoxications in the maritime shipping sector: Belgian and French reported cases. Int Marit Health. 2020; 71(3): 151-159, doi: 10.5603/IMH.2020.0028, indexed in Pubmed: 33001425.

10. IARC. Methyl bromide. Monographs on the Identification of Carcinogenic Hazards to Humans. International Agency for Research on Cancer, World Health Organisation, Lyon, France. 1999. http:// monographs.iarc.fr.

11. UNEP. Handbook for the Montreal Protocol on Substances that Deplete the Ozone Layer. United Nations Environment Programme, Nairobi, Kenya. 2019. https://ozone.unep.org/sites/default/files/ Handbooks/MP_Handbook_2019.pdf.

12. MBTOC. Report of the Methyl Bromide Technical Options Committee. 2018 Assessment. United Nations Environmental Programme, Nairobi, Kenya. 2019. https://ozone.unep.org/sites/default/ files/2019-04/MBTOC-assessment-report-2018_1.pdf (2018).

13. Lyubimov AV, Garry VF. Phoshine. In: Krieger R, ed. Hayes' Handbook of Pesticide Toxicology. 3 ed. Academic Press, London, UK 2010: 2259-2266.

14. Omae $\mathrm{K}$, Ishizuka $\mathrm{C}$, Nakashima $\mathrm{H}$, et al. Acute and subacute inhalation toxicity of highly purified phosphine $\left(\mathrm{PH}_{3}\right)$ in male ICR mice. J Occup Health. 1996; 38(1): 36-42, doi: 10.1539/joh.38.36.
15. Newton P, Schroeder R, Sullivan J, et al. Inhalation toxicity of phosphine in the rat: acute, subchronic, and developmental. Inhal Toxicol. 2008; 5(2): 223-239, doi: 10.3109/08958379309034503.

16. Morgan DL, Moorman MP, Elwell MR, et al. Inhalation toxicity of phosphine for Fischer 344 rats and B6C3F1 mice. Inhal Toxicol. 1995; 7(2): 225-238, doi: 10.3109/08958379509029095.

17. Newton PE, Hilaski RJ, Banas DA, et al. A 2-year inhalation study of phosphine in rats. Inhal Toxicol. 1999; 11(8): 693-708, doi: 10.1080/089583799196817, indexed in Pubmed: 10477443.

18. Wong B, Lewandowski R, Tressler J, et al. The physiology and toxicology of acute inhalation phosphine poisoning in conscious male rats. Inhal Toxicol. 2017; 29(11): 494-505, doi: 10.1080/08958378.2017.1406564, indexed in Pubmed: 29251003.

19. Bast C, Falke E. Phosphine and eight metal phosphides. Acute Exposure Guideline Levels for Selected Chemicals. National Academy Press, Washington DC, USA. 2008. http://nap.edu/12018.

20. Nath NS, Bhattacharya I, TuckAG, et al. Mechanisms of phosphine toxicity. J Toxicol. 2011; 2011: 494168, doi: 10.1155/2011/494168, indexed in Pubmed: 21776261.

21. Sciuto AM, Wong BJ, Martens ME, et al. Phosphine toxicity: a story of disrupted mitochondrial metabolism. Ann N Y Acad Sci. 2016; 1374(1): 41-51, doi: 10.1111/nyas.13081, indexed in Pubmed: 27219283.

22. Vohra RB, Schwarz KA, Williams SR, et al. Phosphine toxicity with echocardiographic signs in railcar stowaways. Abstracts of the 2006 North American Congress of Clinical Toxicology Annual Meeting, Clin Toxicol. 2006; 44: 719-720.

23. Pepelko B, Seckar J, Harp PR, et al. Worker exposure standard for phosphine gas. Risk Anal. 2004; 24(5): 1201-1213, doi: 10.1111/j.0272-4332.2004.00519.x, indexed in Pubmed: 15563288.

24. Proudfoot AT. Aluminium and zinc phosphide poisoning. Clin Toxicol (Phila). 2009; 47(2): 89-100, doi: 10.1080/15563650802520675, indexed in Pubmed: 19280425.

25. Potter WT, Garry VF, Kelly JT, et al. Radiometric assay of red cell and plasma cholinesterase in pesticide appliers from Minnesota. Toxicol Appl Pharmacol. 1993; 119(1): 150-155, doi: 10.1006/ taap.1993.1054.

26. Barbosa A, Bonin AM. Evaluation of phosphine genotoxicity at occupational levels of exposure in New South Wales, Australia. Occup Environ Med. 1994; 51(10): 700-705, doi: 10.1136/oem.51.10.700, indexed in Pubmed: 8000496.

27. Schaefer GJ, Newton PE, Gruebbel MM, et al. Acute and subacute inhalation neurotoxicity of phosphine in the rat. Inhal Toxicol. 1998; 10: $293-320$.

28. Wilson R, Lovejoy FH, Jaeger RJ, et al. Acute phosphine poisoning aboard a grain freighter. Epidemiologic, clinical, and pathological findings. JAMA. 1980; 244(2): 148-150, indexed in Pubmed: 7382074.

29. Lemoine TJ, Schoolman K, Jackman G, et al. Unintentional fatal phosphine gas poisoning of a family. Pediatr Emerg Care. 2011; 27(9): 869-871, doi: 10.1097/PEC.0b013e3182348e40, indexed in Pubmed: 21926889.

30. Brautbar N, Howard J. Phosphine toxicity: report of two cases and review of the literature. Toxicol Ind Health. 2002; 18(2): 71-75, doi: 10.1191/0748233702th133oa, indexed in Pubmed: 12868795.

31. Waszkowska M, Walusiak-Skorupa J, Merecz-Kot D, et al. [Late effects of mass acute phosphine poisoning. Case report]. Med Pr. 2018; 69(3): 337-344, doi: 10.13075/mp.5893.00648, indexed in Pubmed: 29565044. 
32. Szymczyk E, Wiszniewska M, Walusiak-Skorupa J, et al. Subclinical chronic left ventricular systolic dysfunction resulting from phosphine poisoning. Occup Med (Lond). 2017; 67(3): 233-235, doi: 10.1093/ occmed/kqx005, indexed in Pubmed: 28339702.

33. Ziemer U. [Fatal hydrogen phosphide poisoning on a freighter]. Zentralbl Arbeitsmed. 1963; 13: 38-39, indexed in Pubmed: 14003625.

34. MAIB. Report on the investigation into the release of phosphine gas during cargo discharge on board Arklow Meadow, Warrenpoint, Northern Ireland on 5 December 2012. Marine Accident Investigation Branch, Southampton, UK. 2013. https://www.gov. uk/maib-reports/release-of-phosphine-gas-during-discharge-offumigated-maize-cargo-from-general-cargo-vessel-arklow-meadowat-warrenpoint-northern-ireland.

35. MAIB. Phosphine poisoning on general cargo vessel Monika with loss of 1 life. Marine Accident Investigation Branch, Southampton, UK. 2008. https://www.gov.uk/maib-reports/phosphine-poisoningon-general-cargo-vessel-monika-with-loss-of-1-life.

36. Loddé B, Lucas D, Letort JM, et al. Acute phosphine poisoning on board a bulk carrier: analysis of factors leading to a fatal case. J Occup Med Toxicol. 2015; 10: 10, doi: 10.1186/s12995-0150050-0, indexed in Pubmed: 25763098.

37. Gard. Fumigation of cargo on board ships: the invisible killer. Gard News 204, Gard AS. 2011. http://www.gard.no/web/updates/content/20650371/fumigation-of-cargo-on-board-ships-the-invisible-killer.

38. Afandiyev I. Mass phosphine poisoning on board a cargo ship. Clin Toxicol (Phila). 2020; 58(6): 520.

39. Belobrov E, Torskiy V, Rangayeva G. Analysis of accidents during maritime transportation of cargo fumigated with phosphine: Causes, consequences, prevention. In: Weintrit A, Neumann T, eds. Advances in marine navigation and safety of sea transportation. CRC Press, Taylor \& Francis Group, London, UK 2019: 99-104.

40. IMO. Recommendations on the safe use of pesticides in ships applicable to the fumigation of cargo holds. MSC.1/Circ.1264, International Maritime Organization, London, UK. 2008.

41. Kalbarczyk-Jedynak A, Stochla D, Kostecka E. Safety on-board a ship vs knowledge of the chemical processes discussed at the level of high school. Gen Prof Educat. 2018; 3: 39-44.
42. MSAH. HTP-VÄRDEN 2020. Koncentrationer som befunnits skadliga (Occupational exposure limits, in Swedish). Ministry of Social Affairs and Health in Finland, Helsinki, Finland. 2020. https://julkaisut. valtioneuvosto.fi/handle/10024/162458 (Accessed November 26, 2020).

43. SWEA. Hygieniska gränsvärden (Occupational exposure limits, in Swedish). Swedish Work Environment Authority, Stockholm, Sweden. 2018. https://www.av.se/globalassets/filer/publikationer/ foreskrifter/hygieniska-gransvarden-afs-2018-1.pdf (Accessed November 26, 2020).

44. DWEA. Grænseværdier for luftforureninger m.v. (Limit Values for Air Contaminants, in Danish). Danish Working Environment Authority, Copenhagen, Denmark. 2020. https://at.dk/regler/bekendtgoerelser/graensevaerdier-stoffer-materialer-698/bilag-2/ (Accessed November 26, 2020).

45. BAUA. TRGS 900 Technical Rules for Hazardous Substances (in German). Bundesanstalt für Arbeitsschutz und Arbeitsmedizin., Dortmund, Germany. 2020. https://www.baua.de/DE/Angebote/ Rechtstexte-und-Technische-Regeln/Regelwerk/TRGS/pdf/TRGS900.pdf?_blob=publicationFile (Accessed November 26, 2020).

46. NIOSH. Immediately Dangerous To Life or Health (IDLH) Values. National Institute for Occupational Safety and Health, Centers for Disease Control and Prevention, Washington DC, USA. 2019. https://www. cdc.gov/niosh/idlh/intridl4.html (Accessed November 26, 2020).

47. IARC. Monographs on the identification of carcinogenic hazards to humans. International Agency for Research on Cancer, World Health Organisation, Lyon, France. 2020. http://monographs.iarc.fr (Accessed November 26, 2020).

48. Hansen HL, Pedersen G. Poisoning at sea: injuries caused by chemicals aboard Danish merchant ships 1988-1996. J Toxicol Clin Toxicol. 2001; 39(1): 21-26, doi: 10.1081/clt-100102875, indexed in Pubmed: 11327222.

49. Drouin M. Fumigation gas sickens 16 crewmembers aboard dry bulk ship near Welland Canal. Professional Mariner. Navigator Publishing LLC, Portland, Maine, USA. 2011. http://www.professionalmariner. com/April-2011/Fumigation-gas-sickens-16-crewmembers-aboarddry-bulk-ship-near-Welland-Canal/. 